\title{
No Consistent Methodology Used in Application of RF to Allow Valid Comparisons
}

\section{TO THE EDITOR:}

With interest, we read the article from Simopoulos et al (1). We have extensively utilized pulsed radiofrequency applications for radicular pain for greater than 10 years. As published earlier (1), it is our experience that outcome is directly related to the proximity of the radiofrequency electrode to the targeted neural structure. Thus, positive stimulation at $50 \mathrm{~Hz}$ at less than 0.2 volts would be preferable to accepting higher thresholds of less than 0.6 volts. Moreover, by decreasing tissue impedance with normal saline injection, when necessary, the consistent delivery of greater than 200 milliamps of current was possible without exceeding tissue temperatures of 42 degrees Celsius.
In our study (2), 8 patients have reported satisfactory relief of radicular pain for $7 \pm 3.8$ months. We point out these differences to make the point that there is not a consistent methodology used by investigators in the application of radiofrequency to allow valid comparisons of patient outcomes.

\author{
Dan C. Martin, MD \\ Medical College of Georgia \\ 1120 15th St. \\ Augusta, GA 30912 \\ damartin@mail.mcg.edu
}

\section{Reference}

1. Simopoulos TT, Kraemer J, Nagda JV, Aner M, Bajwa ZH. Response to pulsed and continuous radiofrequency lesioning of the dorsal root ganglion and segmental nerves in patients with chronic lumbar radicular pain. Pain Physician 2008; 11:137-144.
2. Martin DC, Willis ML, Mullinax A, Clarke, NL, Homburger, JABerger IH. Pulsed radiofrequency application in the treatment of chronic pain. Pain Practice 2007; 7:31-35.

\section{In Response}

We would like to thank Dr. Martin for his interest in our article (1). We agree that the optimal technique for applying pulsed radiofrequency to the dorsal root ganglion and spinal segmental nerves has not been established. Therefore one may observe inconsistent results from future randomized controlled trials as was seen with continuous radiofrequency treatments for lumbosacral radicular pain $(2,3)$. Before embarking on larger outcome studies it would be worthwhile to evaluate factors such as the proximity of the radiofrequency cannula to the target neural structure and the surrounding tissue impedance on the magnitude of pain reduction and the duration of relief. There is also debate as to how long pulsed radiofrequency should be applied to the treated dorsal root ganglion/segmental nerve. This aspect of the therapy merits further investigation as well.

During the time of the design of our methods used in our study (2002), we had appreciated positive analgesic effects in patients with chronic lumbosacral radiculopathy when accepting sensory stimulation at $50 \mathrm{~Hz}$ from 0.1 to 0.6 volts. The range of sensory stimulation agrees with other investigators (4). We were not aware that very close needle approximation (e.g. 
0.2 volts versus 0.4 volts) could significantly influence the duration of treatment effect. On a similar note, the impact of impedance on treatment outcome has not been adequately evaluated. Previous authors have reported that impedances of less than 400 should afford adequate current density exposure (5). In conclusion, there is little consensus on whether and how to treat lumbosacral radicular pain with pulsed radiofrequency at the present time.
Thomas T. Simopoulos, MD

Director of Interventional Pain Service

Instructor in Anesthesiology \& Pain Management

Department of Anesthesia \& Critical Care

Harvard Medical School

Beth Israel Deaconess Medical Center

Boston, MA

tsimopou@bidmc.harvard.edu

\section{References}

1. Simopoulos TT, Kraemer J, Nagda JV, Aner M, Bajwa ZH. Response to pulsed and continuous radiofrequency of the dorsal root ganglion and segmental nerves in patients with chronic lumbar radicular pain. Pain Phys 2008;11:137144 .

2. van Wiljk RMAW, Geurts JWM, Wynne HJ. Long-lasting analgesic effect of radiofrequency treatment of the lumbar dor- sal root ganglion. J Neurosurg (Spine 2) 2001; 94:227-31.

3. Geurts JW, van Wijk RM, Wynne HJ, Hammink E, Buskens E, Lousberg R, Knape JT, Groen GJ.Radiofrequency lesioning of dorsal root ganglia for chronic lumbosacral radicular pain: A randomized, 5 . double-blind, controlled trial. Lancet 2003; 361:21-26.

4. Van Zundert J, Lame IE, de Louw A, Jan- sen J, Kessels F, Patijn J, van Kleef M. Percutaneous pulsed radiofrequency treatment of the cervical dorsal root ganglion in the treatment of chronic cervical pain syndromes: A clinical audit. Neuromodulation 2003; 6:6-14.

Sluijter ME, Radiofrequency. In Radiofrequency: Part 1 Flivo Press, Meggen (LU), Switzerland, 2001, pp 64-65. 